\title{
The Rotterdam Elderly Pain Observation Scale (REPOS) is reliable and valid for non- communicative end-of-life patients
}

\author{
Anniek D. Masman ${ }^{1,2,3^{*}}$ D, Monique van Dijk ${ }^{1,3}$, Joost van Rosmalen ${ }^{4}$, Frans P. M. Baar ${ }^{1,2}$, Dick Tibboel ${ }^{1,3}$ \\ and Anneke A. Boerlage ${ }^{1,3}$
}

\begin{abstract}
Background: In palliative care, administration of opioids is often indispensable for pain treatment. Pain assessment may help recognize pain and guide treatment in non-communicative patients. In the Netherlands the Rotterdam Elderly Pain Observation Scale (REPOS) is recommended to this aim, but not yet validated. Therefore the objective of this study was to validate the REPOS in non-communicative or unconscious end-of-life patients.

Methods: In this observational study, the primary researcher applied the REPOS, while both the researcher and a nurse applied the Numeric Rating Scale (NRS). If possible, the patient in question applied the NRS as well. The NRS scores were compared with the REPOS scores to determine concurrent validity. REPOS scores obtained before and after a pain-reducing intervention were analysed to establish the scale's sensitivity to change.

Results: A total of 183 REPOS observations in 100 patients were analysed. Almost 90\% of patients had an advanced malignancy; observations were done a median of 3 days (IQR 1 to 13) before death. Internal consistency of the REPOS was 0.73 . The Pearson product moment correlation coefficient ranged from 0.64 to 0.80 between REPOS and NRS scores. REPOS scores declined with median 2 points (IQR 1 to 4 ) after a pain-reducing intervention ( $p<$ 0.001). Optimal sensitivity (0.81) and specificity (0.62) were found at cut-off score 3.

Conclusions: This study demonstrates that the REPOS has promising psychometric properties for pain assessment in non-communicative end-of-life patients. Its application may be of additional value to relieve suffering, including pain, in palliative care.
\end{abstract}

Keywords: pain measurement, palliative care, terminal care, hospice care, delirium, dementia, amnestic, cognitive disorders, consciousness disorders

\section{Background}

Several studies reported that $45 \%$ to $70 \%$ of patients with incurable cancer, either admitted to a hospice or staying elsewhere, suffer moderate to severe pain [1-3]. Forty-five per cent of those patients receive opioids, which are the strongest analgesics [2, 4]. Pain levels should be accurately assessed to guide pain treatment.

Patients' self-report of pain is considered the "gold standard" for pain assessment [5]. However, in the

\footnotetext{
* Correspondence: anniekmasman@gmail.com

${ }^{1}$ Pain Expertise Centre, Erasmus MC-Sophia Children's Hospital, P.O. Box:

Postbus 2060, 3000, CA, Rotterdam, The Netherlands

${ }^{2}$ Palliative Care Centre, Laurens Cadenza, Oosterhagen 239, 3078, CL,

Rotterdam, The Netherlands

Full list of author information is available at the end of the article
}

terminal phase of life, patients may not be able to selfreport pain. To illustrate this, $68 \%$ to $83 \%$ of patients had cognitive failure [6,7] and $90 \%$ to $98 \%$ of patients were drowsy or unresponsive prior to death [8-10]. Proxy pain assessment by a nurse was needed, therefore, in $90 \%$ of patients in a palliative care unit at the day of death [9]. Assessment of suffering, including pain, is challenging anyway in the terminal phase, especially in sedated patients [11].

Proxy assessment often underestimates the pain level, with consequent risk of under treatment [12, 13]. The risk might be lower if attention is paid to well-defined behaviour indicative for pain. Therefore, application of an observation scale that includes such behaviours (and 
has been validated for the target group) could be more beneficial for non-communicative patients.

We previously developed the Rotterdam Elderly Pain Observation Scale (REPOS, see Additional files 1, 2 and 3) in a study among nursing home residents with speech limitations caused by various disorders. The REPOS is available in Dutch and English [14, 15]. Dutch palliative guidelines recommended the REPOS for specific non-communicative patient groups [16], such as persons with dementia and intellectual disability. It proved a valid tool to measure pain in the nursing home population, including those who could not communicate [14]. However, the REPOS was not yet validated for palliative patients and needed to be re-validated for this population.

Beside the REPOS several other observational pain assessment tools have been developed for specific noncommunicative patients groups [17-19], but to our best of knowledge only one of these has been validated for end-of-life patients, the Multidimensional Objective Pain Assessment Tool (MOPAT) [20]. This tool, published in 2011, was developed for hospice patients who are unable to self-report pain. It was tested in a small sample of 28 alert patients and 30 non-communicative patients and showed good internal consistency and sensitivity to change after a pain-reducing intervention [20]. A disadvantage of the MOPAT, however, is that it includes blood pressure and heart rate measurements, which are often stopped at the end of life, as recommended in the Liverpool Care Pathway for the dying patients [21].

In the Netherlands, the REPOS is increasingly adopted in nursing homes and institutions for intellectually disabled or non-communicative patients [15]. Hospice patients, however, may have other characteristics. They often suffer from advanced cancer ( $>90 \%$ of patients) and are mostly bedridden. Self-report is not possible due to their illness state (comatose, delirium or adverse effects of medication), in contrast to nursing home patients who more often have dementia. In addition, endof-life patients are in another emotional state and may be extremely anxious, facing death. All these aspects may influence experiences or expressions of pain [17].

\section{Methods}

\section{Aim}

The aim of this study was to revalidate the REPOS for pain assessment in non-communicative or unresponsive end-of-life patients.

\section{Design, participants and setting}

This observational study was performed in Laurens Cadenza in Rotterdam. This is the largest palliative care centre in the Netherlands, with 20 beds for end-of-life care and symptom management; 200 to 250 patients are admitted annually. The main admission criterion is having a life expectancy of less than 3 months. Approximately $90 \%$ of the patients have advanced malignant disease. The median length of stay in 2010 was 11 days (IQR 5 to 29) and the discharge rate was $4 \%$ [22]. Dutch palliative guidelines are adhered to [16]. A multidisciplinary team of health care professionals, including caregivers, nurses and elderly care physicians specialized in palliative care, is available $24 \mathrm{~h}$ per day. In addition, many volunteers provide support. Despite a small difference in duration of admission the included patients can be seen as representative of all patients admitted to Cadenza during the year 2010 [22].

\section{Assessment tools}

The Rotterdam Elderly Pain Observations Scale (REPOS) consists of 10 behavioural items (see Additional files 1, 2 and 3), which the observer scores as present or absent after having observed the patient for two minutes preferably during a possible painful moment of care [14]. To optimize inter-observer reliability, a definition chart, which describes all 10 items in detail, and an intervention decision tree are provided (see Additional files 1, 2 and 3). To ascertain sufficient interrater reliability of a REPOS observation, nurses receive training including about 10 bedside paired observations with an experienced REPOS observer [23, 24]. Sufficient interrater reliability is defined as Cohen's kappa $>0.65$. A previous validation study in nursing home residents revealed a significant difference between painful and rest situations and a large correlation with the PAINAD $(r=.75)$ indicating good construct validity. For nursing home residents both the sensitivity $(.85)$ and the specificity (.83) were optimal at a cut-off score of 3 [14]. However, as behaviour might be the result of other emotions than pain, the observer in addition estimates the pain intensity on a Numeric Rating Scale (NRS) from 0 (no pain) to 10 (worst possible pain). Thus, assigning an 'NRS-observer' score is a standard part of the REPOS observation [15]. A REPOS score of 3 or higher in combination with a NRS-observer score of 4 or higher suggests moderate to severe pain for which an intervention is required $[14,25]$. The NRS is considered a valid tool to assess cancer pain intensity $[26,27]$.

\section{Procedure}

Data were collected during three phases, based on the implementation of REPOS and its use in standard care in Laurens Cadenza: training, application in daily practice, and sensitivity-to-change data collection.

First, from March to October 2010, the primary investigator (A.M.) trained nurses in Laurens Cadenza to assess pain with the REPOS, since at that time symptom measurement was not a standard of care. Firstly, the primary investigator performed 10 bedside observations simultaneously with an experienced REPOS observer, to ascertain sufficient interrater reliability for her. As Cohen's kappa 
for the primary investigator was established at 0.76 , she was qualified to perform REPOS observations in this study. November-December 2010, NRS and REPOS assessments were implemented in daily practice for all noncommunicative or unresponsive patients. All trained nurses achieved good interrater reliability with the primary investigator after 6 to 10 paired observations (Cohen's kappa values ranged from 0.70 to 0.78 ).

Second, from January 2011 to May 2012, the primary investigator or a trained nurse assigned a REPOS score and an NRS-observer score in daily practice as standard of care.

Third, from February to June 2013, the second investigator (A.B.) was called in when a patient received a pain-reducing intervention and assigned a REPOS score just before and at least one hour after this intervention. These pre- and post-intervention data were used for the sensitivity-to-change analysis.

To determine internal consistency, concurrent validity and the optimal cut-off score, all REPOS observations made during the three different phases were included, with the exception that regarding the training phase only the observations by the primary investigator were selected and not those of the nurses in training. For the sensitivity-to-change analysis only the pre- and postintervention data from phase three were used.

The type of pain assessment (REPOS observation or self-report) depended on the patient's ability to communicate. In the case of non-communicative or unresponsive patients, the primary investigator assigned a REPOS score and a NRS (NRS-observer), and also the caregiving nurse assigned a NRS score (NRS-proxy). Communicative patients reported in addition to the REPOS score an NRS score themselves (NRS-patient).

\section{Other variables}

Demographic characteristics (age, gender, diagnoses, and duration of admission) were extracted from the electronic medical records; the primary diagnoses and the number of comorbidities were evaluated. The primary diagnoses refer to the WHO's International Classification of Diseases (ICD-10 classification) coding for the patient's terminal illness.

Analgesics prescribed at the time of observation were retrieved from the patients' medical file and classified according to the WHO three-step pain ladder as step 1 (non-opioids; acetaminophen and NSAIDs), step 2 (weak opioids) and step 3 (strong opioids) [28, 29]. The highest-step analgesic prescribed for a patient over all the observations is given in the results section under the heading patient characteristics.

\section{Data analysis}

Data are presented as mean (standard deviation; SD) in case of normally distributed variables and as median (interquartile range $=\mathrm{IQR}$ or minimummaximum range $=$ range) in case of non-normally distributed variables.

To determine interrater reliability, Cohen's kappa was applied for the primary and second investigator and for all nurses who assigned REPOS scores, and defined as good if $\geq 0.65$ [30].

Cronbach's alpha coefficient served to examine the internal consistency reliability of the REPOS items; a value of at least 0.70 is considered good reliability $[31,32]$. Pearson product moment correlation coefficient was applied to determine concurrent validity of the REPOS with the NRS scores. This validity coefficient should exceed 0.30 [33]. The Wilcoxon signed rank test served to estimate sensitivity to change after a pain intervention. The optimal cut-off value for REPOS score was determined as the best combination of sensitivity and specificity comparing the REPOS total scores with NRS proxy as reference.

The correlations between the REPOS, NRS proxy and NRS observer in a repeated measurements setting were calculated with linear mixed modelling using the method proposed by Hamlett et al. [34]. In the linear mixed model, we adjusted the outcomes REPOS, NRS proxy and NRS observer for the independent variables gender, assessment number (repeated assessments per person) and time to death.

Data analyses were performed using IBM SPSS Statistics 24. A significance level of 0.05 (two-sided) was used for statistical tests.

\section{Results}

\section{Patient characteristics}

Over the three study phases, 194 REPOS scores were assigned to 103 patients. Data from three patients were excluded from analysis because these observations were not considered end-of-life assessments: one patient had been discharged after the observations were made and in two data had been obtained earlier than three months before death. Data of the remaining 100 patients were included in the analysis. For those included patients, the first (or only) observation was done a median of 3 days (IQR 1 to 13) before death. The median age was 77 years (IQR 67 to 85$), 65 \%$ were female, and the median duration of admission was 28 days (IQR 9 to 51). Advanced malignancy, mainly of digestive and respiratory organs, was the main reason for admission (89\% of patients). Most patients (73\%) were receiving a standing dose of strong opioids combined with a rescue prescription for breakthrough pain. Six percent of all patients had an 'as needed' opioids prescription only, and $11 \%$ received no analgesics at all. Patient characteristics are shown in Table 1. 
Table 1 Patient characteristics

\begin{tabular}{|c|c|}
\hline Characteristics & $N=100$ \\
\hline \multicolumn{2}{|l|}{ Gender in \% } \\
\hline Male / female & $35 / 65$ \\
\hline \multicolumn{2}{|l|}{ Age in years } \\
\hline median (IQR) & 77 (67 to 85) \\
\hline \multicolumn{2}{|l|}{ Duration of admission in days } \\
\hline Median (IQR) & 28 (9 to 51$)$ \\
\hline \multicolumn{2}{|l|}{ Assessments days before death } \\
\hline Median (IQR) & 3 (1 to 13$)$ \\
\hline \multicolumn{2}{|l|}{ Primary diagnose in N (\%) } \\
\hline Neoplasms & 89 \\
\hline Digestive organs & $26(29)$ \\
\hline $\begin{array}{l}\text { Respiratory and intra-thoracic } \\
\text { organs }\end{array}$ & $17(19)$ \\
\hline Female genital organs & $9(10)$ \\
\hline Breast & $7(8)$ \\
\hline $\begin{array}{l}\text { Eye, brain and other parts of } \\
\text { central nervous system }\end{array}$ & $7(8)$ \\
\hline $\begin{array}{l}\text { Lymphoid, hematopoietic and } \\
\text { related tissue }\end{array}$ & $7(8)$ \\
\hline $\begin{array}{l}\text { III - defined, secondary and } \\
\text { unspecified sites }\end{array}$ & $7(8)$ \\
\hline Other & $9(10)$ \\
\hline Disease of nervous system & $\begin{array}{l}4 \text { (acquired brain injury; Parkinson's } \\
\text { disease; systemic atrophy) }\end{array}$ \\
\hline Infectious and parasitic disease & 3 (pneumonia and frailty) \\
\hline Other & $\begin{array}{l}4 \text { (CVA; lung disease, kidney failure, } \\
\text { invalidity) }\end{array}$ \\
\hline \multicolumn{2}{|l|}{ Analgesics in \% } \\
\hline Opioids around the clock & 73 \\
\hline None & 11 \\
\hline Non-opioids around the clock & 9 \\
\hline Opioids as needed & 6 \\
\hline Non-opioids as need & 1 \\
\hline
\end{tabular}

\section{REPOS scores and NRS scores}

The number of REPOS observations for the 100 patients included in the analysis was 183. The REPOS has been applied once in 52 patients and twice or more (range between 2 and 13) in 46. The observations were conducted by the observer when caregivers provided care, i.e. 34\% during washing or dressing, $30 \%$ during posture change, $21 \%$ during rest, $9 \%$ during a transfer, and $6 \%$ in other care situations.

The median REPOS score was 3 (IQR 1 to 5); the median NRS-observer, NRS-proxy and NRS-patient scores were 2 (IQR 0 to 4 ), 3 (IQR 1 to 6) and 6 (IQR 2 to 7), respectively. REPOS scores indicative of pain (3 to 10) were assigned in 55\% (101/183) of observations. Pain was rated moderate to severe (NRS
4 to 10 ) in $30 \%$ to $67 \%$ of NRS scores. All 10 REPOS items were scored as present more frequently in association with NRS scores 4 to 10 than in association with lower NRS scores (Table 2). The items 'tense face,' 'raising upper lip' and 'closing eyes' were the ones most often observed in association with NRS scores of 4 to 10; the items 'fearful look' and 'panicky' the least often (Fig. 1).

\section{Internal consistency}

The Cronbach's alpha coefficient for internal consistency of the REPOS was 0.73 . The item-total correlations ranged from 0.18 to 0.69 , and were below 0.30 for items: panicky, fearful look, moaning and moving body parts.

\section{Concurrent validity}

The REPOS was correlated to the NRS-observer, NRS-proxy and NRS-patient separately. The Pearson product moment correlation coefficient ranged from 0.64 (95\% CI 0.51 to 0.74 ) to 0.80 (95\% CI 0.72 to 0.86) (Table 3). Linear mixed modelling revealed a correlation between 0.64 and 0.78 for the REPOS, NRS proxy and NRS observer corrected for gender, assessment number (repeated assessments per person) and time to death.

Deleting the above-mentioned 4 items with low correlations for internal consistency had hardly any effect on the Pearson coefficients, which then ranged from 0.62 (95\% CI 0.49 to 0.73 ) to 0.80 (95\% CI 0.72 to 0.86 ).

\section{Sensitivity to change}

Twenty-two pairs of before-and-after scores were included for the sensitivity-to-change analysis. Twenty-one concerned a pharmacological pain-reducing intervention; the other pair concerned changing the patient's posture to relieve or prevent pressure sores.

The median REPOS score declined after a painreducing intervention, both pharmacological and nonpharmacological, from 4 (IQR 3 to 6 ) to 1 (IQR 1 to 3 ) with a median reduction of 2 points (IQR 1 to 3 ). This change was statistically significant $(p<0.001)$. The percentage of REPOS scores indicating no pain (score 0 to 2 ) increased from $9 \%(2 / 22)$ to $68 \%(15 / 22)$.

Table 2 Pain assessments results

\begin{tabular}{lll}
\hline & $\begin{array}{l}\text { Median score } \\
\text { (IQR) }\end{array}$ & $\begin{array}{l}\text { Moderate to severe pain } \\
\text { (NRS 4 to 10) } \\
\text { Number of observations (\%) }\end{array}$ \\
\hline $\begin{array}{l}\text { REPOS score }(N=183) \\
\text { NRS-observer }(N=\end{array}$ & $2(1$ to 5$)$ & $101(55)$ \\
$\begin{array}{l}182) \\
\text { NRS-proxy }(N=107)\end{array}$ & $3(1$ to 6$)$ & $47(30)$ \\
NRS-patient $(N=24)$ & $6(2$ to 7$)$ & $16(67)$ \\
\hline
\end{tabular}




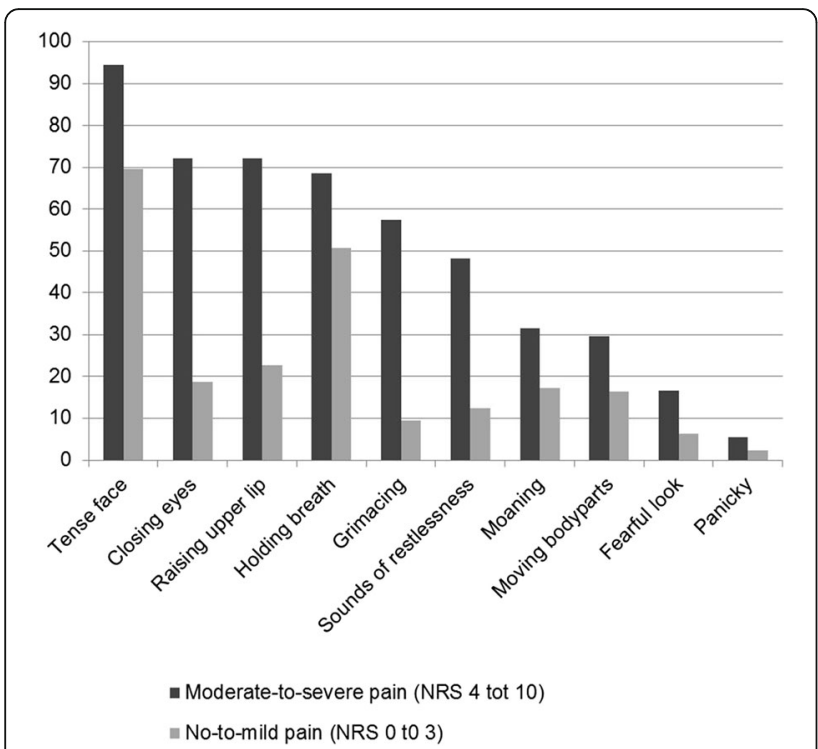

Fig. 1 Percentage of scored REPOS items for no-mild pain and for moderate-to-severe pain

\section{Cut-off score}

In 107 observations, both a REPOS score and a NRSproxy score were available. At the cut-off REPOS score of 3 , sensitivity was 0.81 and specificity was 0.62. The ROC curve, with an AUC of 0.80 (95\% CI 0.71 to 0.88 ), is displayed in Fig. 2. The positive

Table 3 Correlation between REPOS score and the various NRS scores

\begin{tabular}{|c|c|c|c|c|c|}
\hline & & $\begin{array}{l}\text { REPOS } \\
\text { score }\end{array}$ & NRS-observer & NRS-proxy & NRS-patient \\
\hline \multirow[t]{3}{*}{$\begin{array}{l}\text { REPOS } \\
\text { score }\end{array}$} & $\begin{array}{l}\text { Number of } \\
\text { observations }\end{array}$ & 183 & 182 & 107 & 24 \\
\hline & $\mathrm{R}$ & - & 0.73 & 0.64 & 0.66 \\
\hline & $95 \% \mathrm{Cl}$ & - & 0.65 to 0.79 & $\begin{array}{l}0.51 \text { to } \\
0.74\end{array}$ & 0.35 to 0.84 \\
\hline \multirow[t]{3}{*}{$\begin{array}{l}\text { NRS- } \\
\text { observer }\end{array}$} & $\begin{array}{l}\text { Number of } \\
\text { observations }\end{array}$ & & 182 & 107 & 24 \\
\hline & R & & - & 0.80 & 0.77 \\
\hline & $95 \% \mathrm{Cl}$ & & - & $\begin{array}{l}0.72 \text { to } \\
0.86\end{array}$ & 0.53 to 0.90 \\
\hline \multirow[t]{3}{*}{$\begin{array}{l}\text { NRS- } \\
\text { proxy }\end{array}$} & $\begin{array}{l}\text { Number of } \\
\text { observations }\end{array}$ & & & 107 & 24 \\
\hline & R & & & - & 0.72 \\
\hline & $95 \% \mathrm{Cl}$ & & & - & 0.45 to 0.87 \\
\hline \multirow[t]{3}{*}{$\begin{array}{l}\text { NRS- } \\
\text { patient }\end{array}$} & $\begin{array}{l}\text { Number of } \\
\text { observations }\end{array}$ & & & & 24 \\
\hline & $\mathrm{R}$ & & & & - \\
\hline & $95 \% \mathrm{Cl}$ & & & & - \\
\hline
\end{tabular}

Note. Abbreviations: REPOS Rotterdam Elderly Pain Observation Scale, NRS Numeric Rating Scale, $R$ Pearson correlation, $C l$ Confidence Interval predictive value was 0.62 and the negative predictive value was 0.80 .

In $21 \%(23 / 107)$ of observations the REPOS score was indicative for pain (score 3-10) whereas the NRS-proxy score was not; suggesting false-positive outcomes of the REPOS. In contrast, in 8\% (9/107) of observations the REPOS score did not indicate pain (score 0-2) whereas the NRS-proxy score did (score 4-10), suggesting false-negative outcomes.

\section{Discussion}

The findings from this study show that the REPOS has promising psychometric properties to assess pain in non-communicative end-of-life patients; including adequate internal consistency, sufficient concurrent validity and good sensitivity to change after a pain-reducing intervention.

A variety of observational pain scales have been developed for other settings where non-communicative patients are treated, including intensive care units [35] and nursing homes [19]. Only one, the MOPAT [20], has been validated for non-communicative end-of-life patients, albeit preliminary and without establishing a cutoff score. The MOPAT was published after start of our study (2010). We therefore could not use it, although it would have been interesting to compare the two scales.

The overall internal consistency of the REPOS in the present study was adequate as judged from the Cronbach's alpha coefficient of 0.73 [31,32]. Although the item-total correlations of 4 items (panicky, fearful look, moaning and moving body parts) were below 0.30 , we chose to retain those items. These low values could be related to infrequent occurrence of those behaviours in terminally ill patients as they receive high doses of strong analgesics and/or sedatives. For example, the ability to fully react with all body parts is often diminished in the end-of-life stage. In other non-communicative patients who use lower doses analgesics those behaviours might be more obvious. In observations of nursing home residents during a possible painful situation, i.e. washing and clothing or during physiotherapy, when manipulation irritates already affected tissue (i.e. arthritis) all 10 behaviours were seen. Deletion of those 4 items could therefore create a risk of underestimating pain in a broader group of non-communicative patients. The major reason for retaining these items is that the scale should be applicable in other settings with noncommunicative patients as well.

With respect to concurrent validity, a high correlation (0.73) was found - not surprisingly - between REPOS and NRS scores assigned by the same person. The correlation between REPOS and the gold standard (NRS-patient) was only moderate [32], as is seen in other pain scale studies too $[36,37]$. This moderate correlation is 


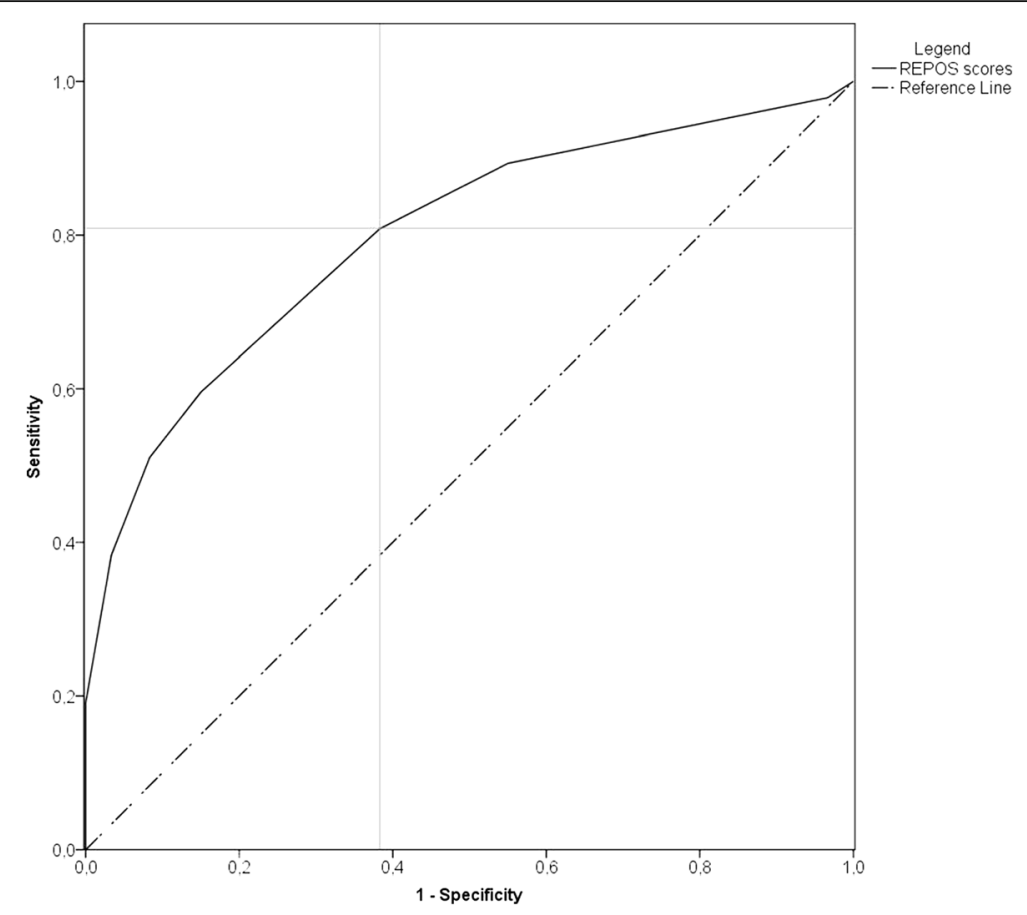

Fig. 2 ROC curve of the optimal sensitivity and specificity for the REPOS score. The full line represents sensitivity and specificity of de REPOS score. The dotted line represents the line for which sensitivity and specificity are equal. A horizontal and a vertical grey line are added to show the optimal cut-off value of the REPOS score

perhaps explained by patient characteristics. Patients who are unable to report pain with the NRS seem to show more nonverbal behaviour, such as grimace [36, 38]. For these patients their pain would be better reflected by a behavioural score than by a proxy NRS only.

It is not unexpected that the REPOS score and the NRS-proxy score may differ to some extent. A high REPOS score combined with a lower NRS-proxy score, or a so-called false positive score, is typically seen in patients who show "emotional" behaviour not related to pain, but based on anger, fear or agitation [39, 40]. The opposite, a false-negative score, may occur when the attending nurse has observed behaviour not included in the REPOS score, such as muscle tension. Alternatively, the nurse's NRS score reflects knowledge of relevant characteristics, such as history or medication use, illness and other patient specific characteristics [12, 13, 41].

This study showed that the cut-off score of 3 or higher is applicable for non-communicative end-of-life patients. However, application of a 'one-fits-all' cut-off score is debated [42, 43]. A reason suggested in literature is that different underlying conditions cause different types of damage to the brain, and consequently different responsiveness to pain [43-45]. Based on these arguments one could consider the use of an individualized cut-off score, which has been recommended for other vulnerable patients groups, e.g. young children [46]. However, this approach asks more from the caregivers: it is a dynamic approach requiring evaluation and adjustment at regular times and when indicated. As daily pain assessment itself was shown to be problematic [47], one can wonder if an individualized approach is feasible in a daily care situation $[48,49]$.

A strength of the present study is that most observations were done within the last two weeks of life and therefore including even those patients near the time of death. In the previous validation study of the REPOS [14], only a small proportion of the population was at the end of life. In addition, communicative patients rated their pain themselves, which enabled comparison between the REPOS and the gold standard of self-report. Also, the sample size in the present study was 100 patients, which far exceeds the minimal number of 50 patients $[31,50]$.

Some limitations of this study have to be addressed, however. First, this is a single-centre study in mainly advanced cancer patients and care must be exercised in extrapolating the findings to other settings and patients populations, like palliative home care or community-based palliative care. Nevertheless, it seems unlikely that pain behaviour would be different in a different palliative environment. Second, the sensitivity-to-change analysis concerned only a relatively small sample. This limitation is encountered in many other psychometric studies, seeing that researchers often are not available when patients receive additional analgesia and also because nurses may tend to forego reassessment after a pain-reducing intervention [51]. The comparable 
MOPAT study [20] also included fewer patients than planned, mainly due to logistical reasons. The fact that the observer knew whether the patient received pain medication or not, could be considered a weakness of the sensitivity-to-change analysis. In the ideal situation, observers blinded for this condition apply the REPOS when watching video recordings made before and after an intervention. However, it was felt undesirable to ask relatives' approval to film their loved ones in the dying phase for research purposes. Still, knowing that the REPOS is sensitive enough to measure small changes after an intervention means that it is suitable for pharmacodynamic studies, which are urgently needed in this palliative patient group [11]. Lastly, in the present study the REPOS was compared with NRS scores, although a comparison with another behaviour pain scale would have strengthened the reliability and validity testing [52]. In future studies the outcomes of different observational scales like the PACSLAC, PAINAD and MOPAT should be compared and the possibility should be explored if blinded observation is possible.

\section{Conclusions}

In conclusion, the REPOS seems to meet the criteria for the use of a pain measurement tool in palliative care of the Expert Working Group of the European Association of Palliative Care (EAPC) [53]. That is, the brevity of the scale (10 well-defined behaviors, scored yes/no after a twominute observation period) and the cut-off score increases clinical utility. The scale was validated for nursing home residents with speech limitations and the present study increases the psychometric knowledge about sensitivity to treatment effect and reliability during palliative care. The fact that the REPOS is available in Dutch as well as English can be seen as an advantage as well. In addition, next to the Dutch palliative guidelines [16], the use of the REPOS for pain assessment in non-communicative patients is recommended in a report on quality indicators in palliative care, published by the Netherlands Institute for Health Services Research [54]. We have demonstrated that the REPOS seems a valid tool for the assessment of pain in non-communicative end-of-life patients. We recommend its use on a daily basis for every non-communicative palliative patient. After a brief training course every professional palliative caregiver will be able to use it in daily practice. A REPOS electronic educational module is available (both in Dutch or English) to guide implementation and training [15].

\section{Additional files}

Additional file 1: Rotterdam Elderly Pain Observation Scale (REPOS) score form. (PDF $638 \mathrm{~kb}$ )

Additional file 2: Rotterdam Elderly Pain Observation Scale (REPOS) instruction chart. (PDF $962 \mathrm{~kb}$ )
Additional file 3: Rotterdam Elderly Pain Observation Scale (REPOS) decision tree. (PDF $787 \mathrm{~kb}$ )

\section{Abbreviations}

EAPC: European Association of Palliative Care; IQR: Interquartile range: MOPAT: Multidimensional Objective Pain Assessment Tool; NRS: Numeric Rating Scale; NRS-observer: NRS score assigned by the same person who performed the observation for the REPOS score; NRS-patient: NRS score given by a patient himself; NRS-proxy: NRS score assigned by a caregiving nurse; PAINAD: Pain Assessment in Advanced Dementia; REPOS: Rotterdam Elderly Pain Observation Scale; SD: standard deviation

\section{Acknowledgments}

The authors thank Ko Hagoort for reviewing the manuscript.

\section{Funding}

This research received no specific grant from any funding agency in the public, commercial, or not-for-profit sectors.

\section{Availability of data and materials}

The datasets used and/or analysed during the current study are available from the last author on reasonable request. Please send an email with your request to a.boerlage@erasmusmc.nl.

\section{Authors' contributions}

$A M, A B, J v R$, FB, DT and MvD designed the study. AM and $A B$ conducted the study. AM, AB, JVR and MvD performed the statistical analyses and drafted the manuscript. All authors contributed substantially to the manuscript and approved its final version.

\section{Ethics approval and consent to participate}

This study was approved by the Medical Ethics Review Board of the Erasmus University Medical Center and the institution's local board of directors, and was performed in accordance with the principles of the Declaration of Helsinki and its later amendments. The Medical Ethics Board waived informed consent as pain assessment is seen as standardized care.

\section{Consent for publication}

Not applicable.

\section{Competing interests}

The authors declare that they have no competing interests.

\section{Publisher's Note}

Springer Nature remains neutral with regard to jurisdictional claims in published maps and institutional affiliations.

\section{Author details}

${ }^{1}$ Pain Expertise Centre, Erasmus MC-Sophia Children's Hospital, P.O. Box: Postbus 2060, 3000, CA, Rotterdam, The Netherlands. 'Palliative Care Centre, Laurens Cadenza, Oosterhagen 239, 3078, CL, Rotterdam, The Netherlands. ${ }^{3}$ Intensive Care, Department of Pediatric Surgery, Erasmus MC-Sophia Children's Hospital, P.O. Box: Postbus 2060, 3000, CA, Rotterdam, The Netherlands. ${ }^{4}$ Department of Biostatistics, Erasmus MC, P.O. Box: Postbus 2060, 3000, CA, Rotterdam, The Netherlands.

Received: 20 March 2017 Accepted: 29 January 2018

Published online: 21 February 2018

References

1. Strassels SA, Blough DK, Hazlet TK, Veenstra DL, Sullivan SD. Pain, demographics, and clinical characteristics in persons who received hospice care in the United States. J Pain Symptom Manag. 2006;32(6):519-31.

2. van den Beuken-van Everdingen $M H$, de Rijke JM, Kessels AG, Schouten HC, van Kleef M, Patijn J. High prevalence of pain in patients with cancer in a large population-based study in The Netherlands. Pain. 2007:132(3):312-20.

3. van den Beuken-van Everdingen $M H$, de Rijke JM, Kessels AG, Schouten HC, van Kleef M, Patijn J. Prevalence of pain in patients with cancer: a systematic review of the past 40 years. Ann Oncol. 2007;18(9):1437-49. 
4. Klepstad P, Kaasa S, Cherny N, Hanks G, de Conno F, Research Steering Committee of the EAPC. Pain and pain treatments in European palliative care units. A cross sectional survey from the European Association for Palliative Care Research Network. Palliat Med. 2005;19(6):477-84.

5. Caraceni A, Brunelli C, Martini C, Zecca E, De Conno F. Cancer pain assessment in clinical trials. A review of the literature (1999-2002). J Pain Symptom Manag. 2005;29(5):507-19.

6. Pereira J, Hanson J, Bruera E. The frequency and clinical course of cognitive impairment in patients with terminal cancer. Cancer. 1997;79(4):835-42.

7. Bruera E, Miller L, McCallion J, Macmillan K, Krefting L, Hanson J. Cognitive failure in patients with terminal cancer: a prospective study. J Pain Symptom Manag. 1992;7(4):192-5.

8. Morita T, Tei Y, Inoue S. Impaired communication capacity and agitated delirium in the final week of terminally ill cancer patients: prevalence and identification of research focus. J Pain Symptom Manag. 2003;26(3):827-34.

9. Fainsinger R, Miller MJ, Bruera E, Hanson J, Maceachern T. Symptom control during the last week of life on a palliative care unit. J Palliat Care. 1991;7(1):5-11.

10. Morita T, Ichiki T, Tsunoda J, Inoue S, Chihara S. A prospective study on the dying process in terminally ill cancer patients. Am J Hosp Palliat Care. 1998;15(4):217-22.

11. Deschepper R, Laureys S, Hachimi-Idrissi S, Poelaert J, Distelmans W, Bilsen J. Palliative sedation: Why we should be more concerned about the risks that patients experience an uncomfortable death. Pain. 2013;154(9):1505-8.

12. Kappesser J, Williams AC. Pain estimation: asking the right questions. Pain. 2010;148(2):184-7

13. Solomon P. Congruence between health professionals' and patients' pain ratings: a review of the literature. Scand J Caring Sci. 2001;15(2):174-80.

14. van Herk R, van Dijk M, Tibboel D, Baar FP, de Wit R, Duivenvoorden HJ. The Rotterdam Elderly Pain Observation Scale (REPOS): a new behavioral pain scale for non-communicative adults and cognitively impaired elderly persons. J Pain Manage. 2008;1(4):367-78.

15. REPOS scale [https://comfortassessment.nl/web/index.php/instruments/ repos-nederlands1/]. Accessed Feb 2016.

16. Guidelines for diagnosis and treatment in palliative care [www.pallialine.nl] Accessed Nov 2014

17. Herr K, Coyne PJ, McCaffery M, Manworren R, Merkel S. Pain assessment in the patient unable to self-report: position statement with clinical practice recommendations. Pain Manag Nurs. 2011;12(4):230-50.

18. Zwakhalen SM, Hamers JP, Abu-Saad HH, Berger MP. Pain in elderly people with severe dementia: a systematic review of behavioural pain assessment tools. BMC Geriatr. 2006;6:3.

19. van Herk R, van Dijk M, Baar FP, Tibboel D, de Wit R. Observation scales for pain assessment in older adults with cognitive impairments or communication difficulties. Nurs Res. 2007;56(1):34-43.

20. McGuire DB, Reifsnyder J, Soeken K, Kaiser KS, Yeager KA. Assessing pain in nonresponsive hospice patients: development and preliminary testing of the multidimensional objective pain assessment tool (MOPAT). J Palliat Med. 2011;14(3):287-92.

21. Ellershaw J. Care of the dying: what a difference an LCP makes! Palliat Med. 2007;21(5):365-8.

22. Masman AD, van Dijk M, Tibboel D, Baar FP, Mathot RA. Medication use during end-of-life care in a palliative care centre. Int J Clin Pharm. 2015;37(5):767-75.

23. Cohen J. Statistical power analysis for the behavioral sciences. 2nd ed. New Jersey, US: Lawrence Erlbaum Associates; 1988.

24. Van Herk R, Boerlage A, Baar FP, Tibboel D, De Wit R, Van Dijk M. Evaluation of a pilot project for implementation of REPOS in daily practice. J Pain Manage. 2008;1(4):357-65.

25. Serlin RC, Mendoza TR, Nakamura Y, Edwards KR, Cleeland CS. When is cancer pain mild, moderate or severe? Grading pain severity by its interference with function. Pain. 1995;61(2):277-84.

26. Paice JA, Cohen FL. Validity of a verbally administered numeric rating scale to measure cancer pain intensity. Cancer Nurs. 1997;20(2):88-93.

27. Jensen MP. The validity and reliability of pain measures in adults with cancer. J Pain. 2003:4(1):2-21

28. Zech DF, Grond S, Lynch J, Hertel D, Lehmann KA. Validation of World Health Organization Guidelines for cancer pain relief: a 10-year prospective study. Pain. 1995:63(1):65-76.

29. Grond S, Zech D, Schug SA, Lynch J, Lehmann KA. Validation of World Health Organization guidelines for cancer pain relief during the last days and hours of life. J Pain Symptom Manag. 1991;6(7):411-22.

30. Cohen J. Weighted kappa: nominal scale agreement with provision for scaled disagreement or partial credit. Psychol Bull. 1968;70(4):213-20.
31. De Vet HC, Terwee CB, Mokkink LB, Knol DL. Measurement in medicine: a practical guide (Practical guides to biostatistics and epidemiology). United Kingdom: Cambridge University Press; 2011.

32. Nunnally JC, Bernstein $\boldsymbol{H}$. Psychometric Testing. 3rd ed. New York: McGraw-Hill; 1994.

33. Streiner DL, Norman GR. Health Measurement Scales: A practical guide to their development and use, vol. fourth. New York: Oxford University Press Inc.; 2008.

34. Hamlett A, Ryan L, Serrano-Trespalacios P, Wolfinger R. Mixed models for assessing correlation in the presence of replication. J Air Waste Manag Assoc. 2003:53(4):442-50

35. Li D, Puntillo K, Miaskowski C. A review of objective pain measures for use with critical care adult patients unable to self-report. J Pain. 2008;9(1):2-10.

36. Kaasalainen S, Akhtar-Danesh N, Hadjistavropoulos T, Zwakhalen S, Verreault R. A comparison between behavioral and verbal report pain assessment tools for use with residents in long term care. Pain Manag Nurs. 2013;14(4):e106-14.

37. Kappesser J, Williams AC, Prkachin KM. Testing two accounts of pain underestimation. Pain. 2006;124(1-2):109-16.

38. Hadjistavropoulos T, LaChapelle DL, MacLeod FK, Snider B, Craig KD. Measuring movement-exacerbated pain in cognitively impaired frail elders. Clin J Pain. 2000;16(1):54-63.

39. Hadjistavropoulos T, Voyer P, Sharpe D, Verreault R, Aubin M. Assessing pain in dementia patients with comorbid delirium and/or depression. Pain Manag Nurs. 2008;9(2):48-54.

40. Jordan A, Regnard C, O'Brien JT, Hughes JC. Pain and distress in advanced dementia: Choosing the right tools for the job. Palliat Med. 2012;26(7):873-8.

41. Shugarman LR, Goebel JR, Lanto A, Asch SM, Sherbourne CD, Lee ML, Rubenstein LV, Wen L, Meredith L, Lorenz KA. Nursing staff, patient, and environmental factors associated with accurate pain assessment. J Pain Symptom Manag. 2010;40(5):723-33.

42. van Dijk JF, Kappen TH, van Wijck AJ, Kalkman CJ, Schuurmans MJ. The diagnostic value of the numeric pain rating scale in older postoperative patients. J Clin Nurs. 2012;21(21-22):3018-24.

43. Chan S, Hadjistavropoulos T, Williams J, Lints-Martindale A. Evidencebased development and initial validation of the pain assessment checklist for seniors with limited ability to communicate-II (PACSLAC-II). Clin J Pain. 2014:30(9):816-24

44. Scherder EJ, Plooij B, Achterberg WP, Pieper M, Wiegersma M, Lobbezoo F, Oosterman JM. Chronic pain in "probable" vascular dementia: preliminary findings. Pain Med. 2015;16(3):442-50.

45. de Knegt $N$, Scherder E. Pain in adults with intellectual disabilities. Pain. 2011:152(5):971-4

46. Voepel-Lewis T, Burke CN, Jeffreys N, Malviya S, Tait AR. Do 0-10 numeric rating scores translate into clinically meaningful pain measures for children? Anesth Analg. 2011;112(2):415-21.

47. Franck $L S$, Bruce E. Putting pain assessment into practice: why is it so painful? Pain Res Manag. 2009;14(1):13-20.

48. Allegaert K, Bellieni CV. Analgosedation in neonates: what we know and how we act. Res Rep Neonatol. 2013;3:51-61.

49. Stevens BJ, Johnston CC, Grunau RV. Issues of assessment of pain and discomfort in neonates. J Obstet Gynecol Neonatal Nurs. 1995;24(9):849-55.

50. Mokkink LB, Terwee CB, Patrick DL, Alonso J, Stratford PW, Knol DL, Bouter LM, de Vet HC. The COSMIN study reached international consensus on taxonomy, terminology, and definitions of measurement properties for health-related patient-reported outcomes. J Clin Epidemiol. 2010;63(7):737-45.

51. Herr K, Titler M, Fine P, Sanders S, Cavanaugh J, Swegle J, Forcucci C, Tang $X$. Assessing and treating pain in hospices: current state of evidence-based practices. J Pain Symptom Manag. 2010;39(5):803-19.

52. Zwakhalen SM, Hamers JP, Berger MP. The psychometric quality and clinical usefulness of three pain assessment tools for elderly people with dementia. Pain. 2006:126(1-3):210-20

53. Caraceni A, Cherny N, Fainsinger R, Kaasa S, Poulain P, Radbruch L, De Conno F. Pain measurement tools and methods in clinical research in palliative care: recommendations of an Expert Working Group of the European Association of Palliative Care. J Pain Symptom Manag. 2002;23(3):239-55.

54. Francke AL, Claessen SJJ, Deliens L. [Quality indicators for palliative care: practical guideline for caregivers] "Kwaliteitsindicatoren voor palliatieve zorg: praktische handleiding voor zorgaanbieders". In: NIVEL; 2010. 